\title{
The Role of Value Co-Creation in ICT-based Service Innovation within Tourism Context
}

\author{
Citra Septi Brilliane ${ }^{1 *}$, Santi Novani ${ }^{2}$, Adinda Farhana ${ }^{1}$ \\ ${ }^{1}$ Master of Science in Management, School of Business and Management, Bandung Institute of Technology, Bandung, \\ Indonesia \\ ${ }^{2}$ School of Business and Management, Bandung Institute of Technology, Bandung, Indonesia
}

\begin{abstract}
The rapid development of technology has shifted the conventional tourism industry towards the digitalization of the tourism sector. The emergence of travel booking platforms, as a form of technology-based service innovation, is able to simplify traveling activities and previous works of literature have indicated a positive relationship towards customer satisfaction. However, tourist's behavior has change become more demanding to involve in the creation of value in accordance with their needs and wants. The concept of value co-creation elaborates this issue, offering a new concept of value creation and new roles between service providers and tourists. This study aims to examine value co-creation as mediating variable between IT-based service innovation and customer satisfaction, using DART measurements and SEM-PLS is used to assess the model. The findings prove that IT-based service innovation positively influences value cocreation between users, which can increase customer satisfaction. However, IT-based service innovation does not have a direct impact on customer satisfaction, which indicates that value co-creation fully mediating the relationship between service innovation and customer satisfaction. Thus to enhance customer satisfaction, service providers need to propose service innovation that facilitates customer involvement in value creation, which can be supported by technology.
\end{abstract}

Keywords: Customer satisfaction, Service innovation, Tourism, Travel booking platform, Value co-creation.

\section{INTRODUCTION}

As we are now in the ever-changing era of technology, innovation in the tourism industry is also influenced by the role of information and communication technology (ICT). The evolution of technology over time is almost simultaneous with technology adoption in tourism [1]. Thus, In 2018, technology was used to analyse tourist behaviour and market from generating big data that obtain by various resources such as usergenerated content (online reviews, Twitter tweets, Instagram's photos, etc.), tourist mobility (GPS data, mobile roaming data, etc.), search engine and transaction data [2].

This phenomenon has resulted in radical changes in how service provider delivers tourism services to customers, from conventional travel agents into a multi-channel network that supported by ICT [3]. Moreover, the way value was created is also changes, following redefined roles of the service provider and customers, which required collaboration [4]. Collaboration between the service provider and customers to define and create value together is called value

\footnotetext{
* Correspondence address: Citra Septi Brilliane

Email : citra_septi@sbm-itb.ac.id

Address : Jl. Ganesa No.10, Lb. Siliwangi, Bandung, West Java 40132.
}

co-creation [5]. By engaging customers to cocreate value, the possibility they repurchase and recommend that service to others is increasing [3]. Therefore, value co-creation could enhance customer experiences that lead to higher customer satisfaction [6]. If customers are satisfied with the service offerings, they will develop the intention to purchase again in the future, willing to share their experiences with others, not paying attention to competitor's brand, and even refuse service offerings by other brands [7].

Service platform acts as intermediaries between the service provider and customers to facilitate their interaction and service exchanges [8]. To develop a value co-creation environment, the service provider should ensure a mechanism for interaction with customers, which is explained by the DART model [5]. DART model consists of four elements, which are dialogue, access, risk-benefit, and transparency, to cocreate value together [9]. DART model is well known in works of study, which many of it also use the DART model to assess and implement value co-creation, using either qualitative or quantitative method [10-12]. In terms of service innovation, previous studies found that service innovation can be improved using DART model $[11,13]$. 
The research focused on co-creation with customers is still limited [14]. Therefore, given several links between service innovation, customer satisfaction, and value co-creation with the customer. This research aims to extend previous research regarding service innovation from a value co-creation perspective and investigate the degree of value co-creation to explain the relationship between service innovation and customer satisfaction in the digital tourism context using the DART model. As literature usually considered value co-creation as a predictor variable, this research will examine value co-creation as a variable that mediates the relationship between service innovation and customer satisfaction.

A travel booking platform called Traveloka was used as the empirical evidence of ICT-based service innovation in the tourism context due to its fast-paced development from 2012 until now and equipped with growing service lines and scope. Traveloka becomes the biggest travel booking platform in Indonesia and also one of the unicorn companies from Indonesia. The result of this research contributes to the enrichment of value co-creation literature in the ICT tourism context, and this study's findings have implications for service providers to help them develop their service innovation that engaging customers to participate.

\section{Framework and Hypothesis}

Based on the purposes of this study and previous literatures, the following structure and hypothesis about relationships between service innovation, value co-creation, and customer satisfaction are presented in Fig. 1. To establish value co-creation, providers should innovate continuously. Thus, it could lead customers to actively engage the value co-creation practices [3]. To enhance this practice, IT could support collaboration between the stakeholders and provide better experiences for them [15].

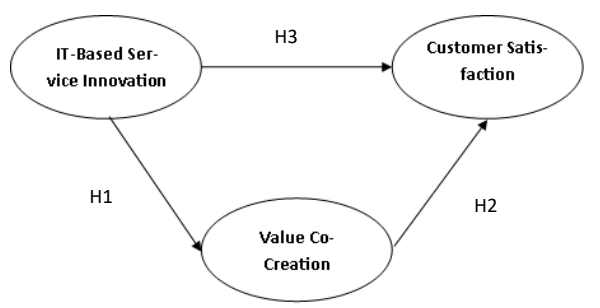

Figure 1. Conceptual framework

Online travel service platform could increase the effectiveness of the value co-creation process because online platform able to integrate stakeholders interaction, for example, between accommodation providers and customers, where customers could co-create more interaction with the providers because they use their own resources, such as knowledge, preferences, time, etc [10]. Therefore, the hypothesis proposed:

Hypothesis $\mathbf{1}\left(\mathbf{H}_{\mathbf{1}}\right)$ : There is a positive relationship between IT-based service innovation and value co-creation.

In terms of customer satisfaction, Prebensen and Xie [16] revealed that through the cocreation process, customer's perceived value could be enhanced, which leads to overall satisfaction towards their experiences. The positive effect of co-creation could also be perceived by the degree of customer satisfaction towards their experiences using the service [17]. Therefore, value co-creation could mediate the relationship between IT-based service innovations with customer satisfaction. Based on the above discussion, the following hypothesis can be proposed:

Hypothesis $\mathbf{2}\left(\mathbf{H}_{\mathbf{2}}\right)$ : There is a positive relationship between value co-creation and customer satisfaction.

Many scholars also have linked the influence of service innovation towards customer satisfaction. Previous studies also indicate positive relationships between service innovation and customer satisfaction in several contexts, whether analyzed with quantitative and qualitative methods [7,13,17-19]. Explored case of tourism factory found that service innovation positively impacts customer satisfaction [7]. ITenabled systems allow customers to participate in shaping their experience also increase customer satisfaction [20]. In order to know whether value co-creation totally mediates the relationship between IT-based service innovation and customer satisfaction, the direct effect between the two variables will also be assessed. Therefore, the following hypothesis is proposed:

Hypothesis $\mathbf{3}\left(\mathbf{H}_{3}\right)$ : There is a positive relationship between IT-based service innovation and customer satisfaction.

\section{MATERIAL AND METHOD Data Collection}

This study was carried out quantitatively. The questionnaire was distributed to Traveloka Indonesian users, who have used Traveloka at least once in the past year. The data was collected using an online questionnaire in 
Indonesian language. The sampling technique used was purposive sampling, and a total of 210 respondents were gathered. The data aim to answer the hypothesis, which was constructed from previous literature.

\section{Measurement}

The questionnaire consists of four sections. Section one about customer's basic information, section two about service innovation. Section three about value co-creation, and section four about customer satisfaction. Basic information of customers was based on study of Yeh et al. [7]. Service innovation scales were based on dimensions from Chen and Tsou [21], which are divided into two categories, namely process innovation and product innovation. The scales were modified following the context of the travel booking platform. Process innovation included seven item which measure new service process regarding website and application, purchasing process, customer service, purchase methods, reschedule feature, cancel and refund feature, and add-on travel features. Product innovation was measured by six items, which are two items regarding service modification and four items about service line extensions.

To measure value co-creation, the DART model was used. According to recent marketing literature, the DART model is considered the most popular framework as guidance to implement value co-creation with customers [22]. DART model consists of four elements, i.e. dialogue, access, risk-benefit and transparency, to co-create value together [9]. Several literatures have evaluated the implementation of the DART model and develop the scale to measure it $[11,12,22]$. DART model is well known, thus many studies also use the DART model to assess and implement value co-creation, using either qualitative or quantitative methods [1012].

Further, this study referred to the scale by Chen et al. [13] and adjusted it with the travel booking platform case. The dialogue was measured by three dimensions including communication, accurate and reliable information exchange, and keeping informed. Access consisted of access to information, facilities, and resources of collaborating partners. The risk assessment included possible risk involvement and quality of problem-solving. The last is transparency with two dimensions, which are clearness of communication network and accessibility of communication network. Each dimension on every variable measured by two items. For customer satisfaction, this study used scale by Ju et al [23], with three dimensions which are overall perception towards service offerings, feeling towards provided service, and intention to use the service in the future. There are two items for each dimension.

\section{RESULT AND DISCUSSION}

\section{Validity of Construct}

Based on the purpose of this study, the partial least squares structural equation modeling (PLSSEM) was done by using SmartPLS 3.0. There are several advantages of PLS-SEM that suitable for this study, which are able to use non-normal data, able to measure reflective and formative constructs, and a small sample size [24].

The composite reliability (CR) and average variance extracted (AVE) were used to measure the reliability and validity of the proposed model. The proposed model initially had three construct variables, which are service innovation with 13 indicators, value co-creation with 20 indicators, and customer satisfaction with seven indicators. In the initial model, CR and AVE did not meet the required threshold value, which was above 0.7 and 0.5 , respectively [25]. Therefore, to increase $C R$ and AVE, the indicator's outer loadings below 0.40 are removed from the model.

The indicator's outer loading is suggested to be higher than 0.70 , while a value between 0.40 and 0.70 should be removed. After removal, CR and AVE values become higher [25]. After factor loading removal, the remaining indicators became seven indicators for service innovation, twelve indicators for value co-creation, and six indicators for customer satisfaction. The discriminant validity was also assessed by a heterotrait-monotrait ratio (HTMT) that the correlation between variables should be below 0.90 [25]. The result of CR, AVE, and HTMT of all constructs are given in Table 1.

\section{Structural Model}

The final framework in Figure 2 shows the relation between IT-based service innovation (ISI) and customer satisfaction (CS) and also the mediation of value co-creation (VCC) between these two variables. To evaluate the structural model, steps suggested by Hair et al. [25] were followed. Path coefficient shows the significance of relationships, bootstrapping procedure was used to measure significance. This model result is shown in Table 2. 
Table 1. Validity of Contructs

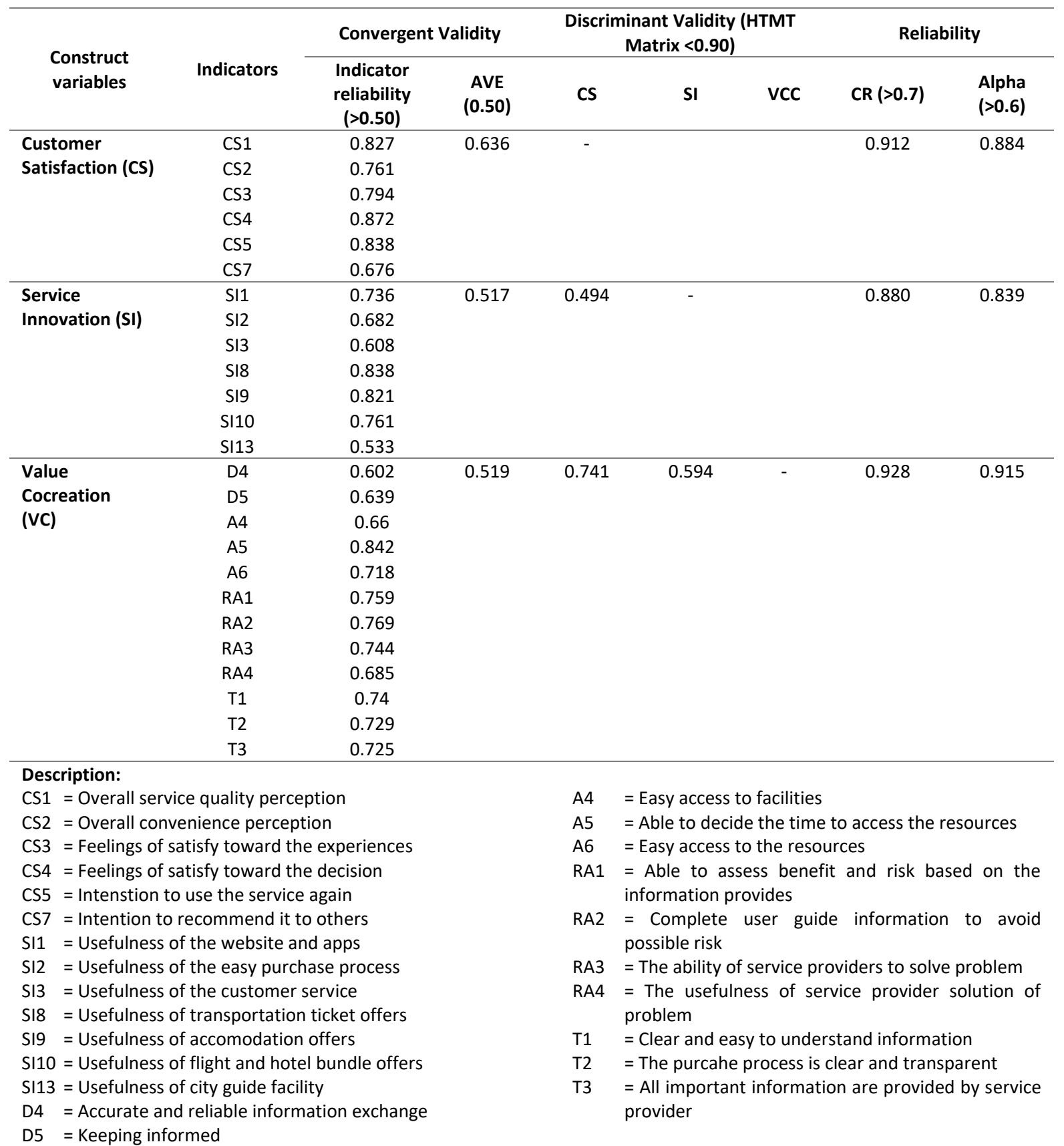

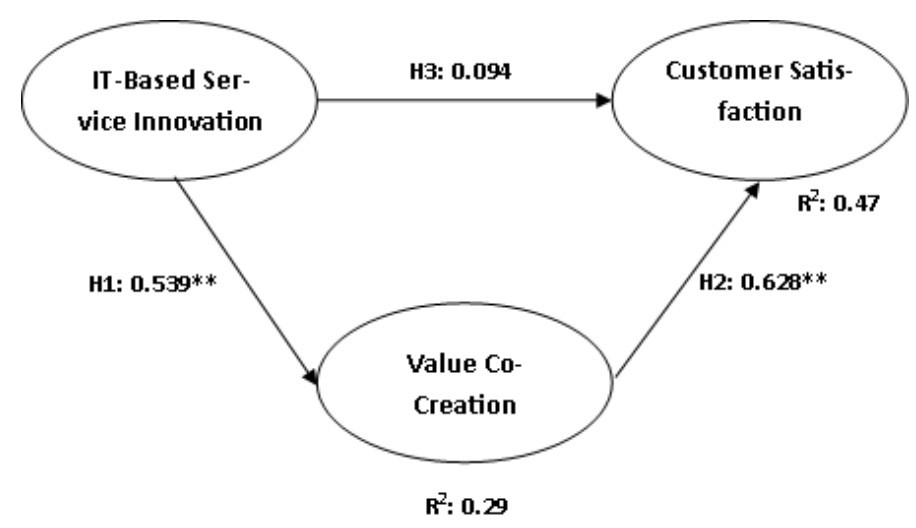

Figure 2. Final framework with significance coefficient 
ICT-based Service Innovation within Tourism Context

(Brilliane, et al.)

Table 2. Structural Model Result

\begin{tabular}{ccccc}
\hline No & \multicolumn{1}{c}{ Causal Relation } & Hypothesis & Standardized $\beta$ coef & T-value \\
\hline $\mathrm{H}_{1}$ & $\mathrm{ISI}->\mathrm{VCC}$ & Supported & $0.539^{* *}$ & 1.534 \\
$\mathrm{H}_{2}$ & $\mathrm{VCC}->\mathrm{CS}$ & Supported & $0.628^{* *}$ & 11.555 \\
$\mathrm{H}_{3}$ & $\mathrm{ISI}->\mathrm{CS} \quad$ Not supported & 0.094 & 13.105 \\
\hline & & &
\end{tabular}

Table 3. Effect Size of Constructs

\begin{tabular}{lcc}
\hline \multicolumn{1}{c}{ Constructs } & $\begin{array}{c}\text { Value Co } \\
\text { Creation }\end{array}$ & $\begin{array}{c}\text { Customer } \\
\text { Satisfaction }\end{array}$ \\
\hline IT-Based Service Innovation & 0.539 & 0.433 \\
Value Co-Creation & & 0.628 \\
\hline
\end{tabular}

Hypothesis $\left(\mathrm{H}_{1}\right)$ that establishes the relationship between service innovation and value co-creation is supported $(\beta=0.539, p$-value $<0.001)$, Hypothesis $\left(H_{2}\right)$ that illustrates the relationship between value co-creation and customer satisfaction is supported $(\beta=0.628, p$ value<0.001). However, the direct effect between service innovation and customer satisfaction is not significant $(\beta=0.094, p$-value $=$ 0.132). Therefore, Hypothesis $\left(\mathrm{H}_{3}\right)$ is not supported. It means that value co-creation is fully mediating the relationship between service innovation and customer satisfaction because only the indirect effect that supported, while the direct effect is not significant. The value of coefficient determination (R2) of the endogenous construct, indicates that service innovation explained 29 percent of the variance in value cocreation, while service innovation and value cocreation explained 47 percent of the variance in customer satisfaction.

The next assessment is the effect size of relationships (f2) between construct variable which can be seen in Table 3. Effect size between 0.25 and 0.15 is considered low, while between 0.15 and 0.30 is considered medium, and above 0.30 is high [26]. The last assessment is the predictive relevance (Q2) for the endogenous construct that should be above zero [25]. The Q2 value of customer satisfaction is 0.292 and for value co-creation is 0.145 , which means that the exogenous construct has predictive relevance over endogenous constructs.

\section{DISCUSSION}

The results showed that value co-creation fully mediated the relationship between IT-based service innovation and customer satisfaction. ITbased service innovation could serve as a platform that enables the actors in the system to co-create value. This mechanism of value cocreation leads to customer satisfaction. It means that value co-creation underlies the relationship between IT-based service innovation and customer satisfaction. Service innovation that is supported by IT, enables efficient and effective value co-creation practices [8]. The empirical results indicate that travel booking platform as a form of IT-based service innovation leads customers and service providers to co-create value. Dialog, access, risk assessment, and transparency had significant factor loadings on value co-creation construct, which indicated that Traveloka as the intermediary platform between customers and service providers plays important roles in enabling these four elements to engage customers in co-creation activity. Therefore, utilizing ICT in the tourism context is important to serve both customers and service providers need to exchange resources.

Moreover, the results show a significant relationship between value co-creation and customer satisfaction. Thus, to increase customer's satisfaction level towards the service, better collaboration between customers and service providers is needed. On the other hand, the direct relationship between ICT-based service innovation towards customer satisfaction is not significant. It indicates that if service provider develops technology-based service innovation only, it does not directly make customer satisfy. Instead, the service provider should pay attention to the customer participation aspect and innovate a platform that could help customers to better engage in the system with technology utilization. In this study, that aspect is represented by the value co-creation concept by Prahalad and Ramaswamy [9], which is the DART model. Thus, the service innovation that service providers develop should fulfill the four elements of DART.

The research findings indicate the importance of technology and value co-creation to increase customer satisfaction. Traveloka becomes an example in the tourism context where technology could facilitate users' value cocreation to enhance service offerings towards customers. The findings suggested that service providers in the tourism industry should utilize technology in making innovation. Adoption of technology in tourism activities can increase competitive advantage becoming a Smart Tourism destination [27]. 
Since value co-creation plays a significant role in increasing customer satisfaction, this study suggests that technology utilization is not only to cope up with the Smart Tourism trend but also to have better engagement with customers in the tourism activities. Thus, tourism service providers should come up with an innovation that could facilitate customers to collaborate in creating value. For example, service providers, particularly in Indonesia, could adopt the Traveloka mechanism and also correspond to the DART model in building service innovation to facilitate customer collaboration and interaction that enable by IT, such as a mobile platform where customers could customize their own tourism activity that offered by service providers.

\section{CONCLUSION}

The results supported hypotheses 1 and 2, which show the relationship between IT-based service innovation to value co-creation and value co-creation to customer satisfaction. Meanwhile, hypothesis 3 showed a direct relationship between IT-based service innovation towards customer satisfaction is not supported. It shows that value co-creation fully mediating the relationship between IT-based service innovation and customer satisfaction. Based on the findings of this study, service innovation should engage customers in co-creation activity to increase their satisfaction. Therefore, service providers should aware that facilitating customers in value creation is important, and technology could become the means to facilitate it. Service providers should ensure that the new innovation they created is accessible for customers to participate and following the DART model could become the first step in implementing value cocreation in service innovation that is offered to customers.

This study has several limitations that require further investigation. The first one is this study only considered the customer side as the impact of value co-creation and did not address the impact on service providers. Therefore, it is recommended to analyzed the consequences of value co-creation for the service providers for further study. The second limitation is the model in this study gives room for improvement, which could be extended by adding new construct that elaborate factors that determine value cocreation and also further implication towards customer loyalty and bigger scope towards tourism sustainability. The third limitation is the basic information of respondents is used to know who is the respondents of the questionnaire. Future study also can identify which tourist characteristics that are more willing to engage in value co-creation. Another limitation of this study is, it is only focused on technology-based service innovation. Therefore, identification regarding non-technological service innovation from a value co-creation perspective also can be assessed.

\section{REFERENCES}

[1] Aldebert, B., R.J. Dang, and C. Longhi. 2011. Innovation in the tourism industry: The case of Tourism@. Tourism Management 32(5), 1204-1213.

[2] Li, J., L. Xu, L. Tang, S. Wang, and L. Li. 2018. Big data in tourism research: A literature review. Tourism Management 68, 301-323.

[3] Grissemann, U. S., and N. E. StokburgerSauer. 2012. Customer co-creation of travel services: The role of company support and customer satisfaction with the co-creation performance. Tourism Management 33(6), 1483-1492.

[4] de Oliveira, D. T., and M. N. Cortimiglia. 2017. Value co-creation in web-based multisided platforms: A conceptual framework and implications for business model design. Business Horizons 60(6), 747758.

[5] Prahalad, C. K., and V. Ramaswamy. 2004. Co-creation experiences: The next practice in value creation. Journal of Interactive Marketing 18(3), 5-14.

[6] González-Mansilla, Ó., G. Berenguer-Contrí, and A. Serra-Cantallops. 2019. The impact of value co-creation on hotel brand equity and customer satisfaction. Tourism Management 75, 51-65.

[7] Yeh, T. M., S. H. Chen, and T. F. Chen. 2019. The relationships among experiential marketing, service innovation, and customer satisfaction-A case study of tourism factories in Taiwan. Sustainability (Switzerland) 11(4), 1-12.

[8] Lusch, R. F., and S. Nambisan. 2015. Service Innovation: A Service-Dominant Logic Perspective. MIS Quarterly 39(1), 155-175.

[9] Prahalad, C. K., and V. Ramaswamy. 2004. Co-creating unique value with customers. Chicago, \{IL:\} National Patient Safety Foundation 32(3), 460-5512.

[10] Smaliukiene, R., L. Chi-Shiun, and I. Sizovaite. 2014. Consumer value co-creation in online business: the case of global travel 
services. Journal of Business Economics and Management 16(2), 325-339.

[11] Taghizadeh, S. K., K. Jayaraman, I. Ismail, and S. A. Rahman. 2016. Scale development and validation for DART model of value cocreation process on innovation strategy. Journal of Business and Industrial Marketing 31(1), 24-35.

[12] Albinsson, P. A., B. Y. Perera, and P. T. Sautter. 2016. DART scale development: Diagnosing a firms readiness for strategic value co-creation. Journal of Marketing Theory and Practice 24(1), 42-58.

[13] Chen, J. S., D. Kerr, C. Y. Chou, and C. Ang. 2017. Business co-creation for service innovation in the hospitality and tourism industry. International Journal of Contemporary Hospitality Management 29(6), 1522-1540.

[14] Mazur, J., and P. Zaborek. 2016. Organizational culture and open innovation performance in Small and Medium-sized Enterprises ( SMEs) in Poland. International Journal of Management and Economics (51), 104-137.

[15] Guimont, D., and D. Lapointe. 2015. Cocreation of a tourist experience enhanced by technology, in the context of a Living Lab vation ecosystem. E-Review of Tourism Research, ENTER 2(1), 1-5.

[16] Prebensen, N. K., and J. Xie. 2017. Efficacy of co-creation and mastering on perceived value and satisfaction in tourists' consumption. Tourism Management 60, 166-176.

[17] Buonincontri, P., A. Morvillo, F. Okumus, and M. van Niekerk. 2017. Managing the experience co-creation process in tourism destinations: Empirical findings from Naples. Tourism Management 62, 264-277.

[18] Fan, S. S., Y. C. Chen, and L. Miao. 2018. Discussing the effect of service innovation on customer satisfaction based on statistics education - A case on Qianjiangyue Leisure Farm. Eurasia Journal of Mathematics, Science and Technology Education 14(6), 2467-2474.

[19] Barile, S., M. V. Ciasullo, O. Troisi, and D. Sarno. 2017. The role of technology and institutions in tourism service ecosystems. The TQM Journal 29(6), 811-833.

[20] Cabiddu, F., T. W. Lui, and G. Piccoli. 2013. Managing value co-creation in the tourism industry. Annals of Tourism Research 42, 86-107.
[21] Chen, J. S., and H. T. Tsou. 2007. Information technology adoption for service innovation practices and competitive advantage. Proceedings - ICSSSM'06: 2006 International Conference on Service Systems and Service Management 12(3), 472-477.

[22] Mazur, J., and P. Zaborek. 2015. Validating DART model. International Journal of Management and Economics 44(1), 106125.

[23] Ju, Y., K. J. Back, Y. Choi, and J. S. Lee. 2019. Exploring Airbnb service quality attributes and their asymmetric effects on customer satisfaction. International Journal of Hospitality Management 77, 342-352.

[24] Hsu, S. H. 2008. Developing an index for online customer satisfaction: Adaptation of American Customer Satisfaction Index. Expert Systems with Applications 34(4), 3033-3042.

[25] Hair, J. F., G. T. M. Hult, C. M. Ringle, and M. Sarstedt. 2017. A primer on Partial Least Squares Structural Equation Modeling (PLSSEM). Long Range Planning Vol. 46.

[26] Kasiri, L., K. Guan-Cheng, M. Sambasivan, and S. Sidin. 2017. Integration of standardization and customization: Impact on service quality, customer satisfaction, and loyalty. Journal of Retailing and Consumer Services 35, 91-97.

[27] Vecchio, P., G. Mele, V. Ndou, and G. Secundo. 2018. Creating value from social big data: implications for smart tourism destinations. Information Processing \& Management 54(5), 847-860. 